TERRITÓRIO E MEMÓ DOS ASURINI DO XIN ZQUEOLOGIA COLABORATIVA T.I. KUATINEMU, P 


\section{TERRITÓRIO E MEMÓRIA DOS ASURINI DO XINGU: ARQUEOLOGIA COLABORATIVA NA T.I. KUATINEMU, PARÁ}

\section{FA B ÍOLA ANDRÉA SILVA}

UniVersidade de SÃo PAUlO, SÃo PAUlO/SP, BRASIL

LORENA LUANA WANESSA GOMES GARCIA

UNIVERSIDAde De SÃo PAUlO, SÃO PAUlO/SP, Brasil 


\section{TERRITÓRIO E MEMÓRIA DOS ASURINI DO XINGU: ARQUE- OLOGIA COLABORATIVA NA T.I. KUATINEMU, PARÁ}

\section{Resumo}

Neste trabalho apresentaremos os primeiros resultados do projeto Território e Memória dos Asurini do Xingu: Arqueologia Colaborativa na T.I. Kuatinemu, Pará. Trata-se da continuidade da pesquisa arqueológica colaborativa que vem sendo realizada com os Asurini do Xingu, desde 2009. Descreveremos o trabalho de campo e as características dos sítios arqueológicos localizados na área. Além disso, faremos uma reflexão sobre a relação entre paisagem e memória neste contexto amazônico de pesquisa.

Palavras-chave: Arqueologia colaborativa, Asurini do Xingu, paisagem, memória.

\section{TERRITORY AND MEMORY AMONG THE ASURINI DO XIN- GU: COLLABORATIVE ARCHAEOLOGY IN THE KUATINEMU INDIGENOUS LAND, PARÁ}

\footnotetext{
Abstract

This paper present the first results of the project: Territory and Memory of the Asurini do Xingu: Collaborative Archaeology at T.I. Kuatinemu, Pará. The project is a continuation of the collaborative archaeological research that has been done with Asurini Xingu, since 2009. We will describe fieldwork and characteristics of the archaeological sites located in the area. In addition, we will reflect on the relationship between landscape and memory in that Amazonian research context.

Keywords: Collaborative archaeology, Asurini do Xingu, landscape, memory.
} 


\section{TERRITORIO Y MEMORIA DE LOS ASURINI DEL XINGU: AR- QUEOLOGÍA COLABORATIVA EN LA T.I. KUATINEMU, PARÁ}

\section{Resumen}

En este trabajo se presentan los primeros resultados del proyecto: Territorio y Memoria dos Asurini: Arqueología Colaborativa en la T.I. Kuatinemu, Pará. Es la continuación de la investigación arqueológica colaborativa que se ha hecho con los Asurini do Xingu, desde 2009. Nosotros vamos describir el trabajo de campo y las características de los sitios arqueológicos encontrados en la área. Además, haremos una reflexión sobre la relación entre el paisaje y la memoria en este contexto de investigación amazónica.

Palabras clave: Arqueología colaborativa, Asurini do Xingu, paisaje, memoria.

Endereço da primeira autora para correspondência: Museu de Etnologia e Arqueologia, Avenida Professor Almeida Prado, 1466 - Butantã, São Paulo - SP, 05508-070.

E-mail: faandrea@usp.br. 


\section{INTRODUÇÃO}

$\mathrm{O}$ projeto arqueológico Território e $\mathrm{Me}$ mória dos Asurini do Xingu: Arqueologia Colaborativa na T.I. Kuatinemu, PA, Brasil, é parte de uma pesquisa colaborativa que é realizada com os Asurini do Xingu desde 2009. O objetivo principal é entender a história e a dinâmica de ocupação territorial deste povo na área que hoje compreende a Terra Indígena Kuatinemu, mais especificamente, ao longo dos igarapés Ipiaçava e Piranhaquara.

Idealizou-se o projeto a partir das demandas dos próprios Asurini. As velhas gerações queriam revisitar os seus antigos locais de moradia e os jovens queriam conhecer estes lugares e aprender sobre essa etapa da sua história nessas terras do Xingu. A etapa de pesquisa de campo no igarapé Ipiaçava foi realizada em maio de 2011, quando subimos $70 \mathrm{~km}$ do rio e localizamos e prospectamos seis assentamentos dos períodos pré e pós-contato: 1) Kuatinemu; 2) Avatikirera; 3) Kuatinemu Velho; 4) Itapemuí; 5) Akapepugi; 6) Tainviaka. Com exceção das aldeias Avatikirera e Tainviaka, os demais sítios eram multicomponenciais, apresentando vestígios arqueológicos da ocupação Asurini e de ocupações anteriores não-Asurini.

Esses sítios se encontram implantados em terraços fluviais e são constituídos por conjuntos materiais diversificados (vasilhas cerâmicas, artefatos líticos e objetos industrializados). Os locais de implantação dos mesmos apresentavam indícios de manejo florestal (como matas de palmeiras e cipós, áreas de capoeira, trilhas, árvores frutíferas) e terra preta associada ao pacote arqueológico, cuja espessura atingiu até $50 \mathrm{~cm}$ de profundidade (Silva et al. 2011).

Os resultados desta etapa da pesquisa de campo foram muito empolgantes para os Asurini, que imediatamente manifestaram interesse em localizar os mais antigos e numerosos assentamentos ao longo do igarapé Piranhaquara. Assim, em maio de 2013, durante 17 dias, subimos $140 \mathrm{~km}$ do igarapé, onde localizamos e prospectamos 4 antigas aldeias Asurini e 9 sítios arqueológicos não-Asurini. Os detalhes sobre o desenrolar da pesquisa, os seus resultados e a reflexão que pudemos elaborar a partir deles serão o objeto deste artigo.

\section{O CONTEXTO DA PESQUISA}

Os Asurini do Xingu vivem em duas aldeias localizadas às margens do rio Xingu (aldeia Kuatinemu e aldeia Itaaka) na T.I. Kuatinemu que abrange uma área de 387.834 hectares, nos municípios de Altamira e Senador José Porfírio (Figura 1). Trata-se de uma área com relevos constituídos pela presença de colinas, colinas de topo aplainado e inselbergs. No trecho que circunda os igarapés Piranhaquara e Ipiaçava, a geomorfologia é representada, de um lado, por um conjunto de formas de relevo de topos tabulares, conformando feições de rampas, suavemente inclinadas; por outro lado, são comuns as áreas planas resultantes da acumulação fluvial, sujeitas a inundações periódicas, como as várzeas, lagos de meandros, furos e diques aluviais paralelos ao leito atual do rio Xingu (Silva 2012). 


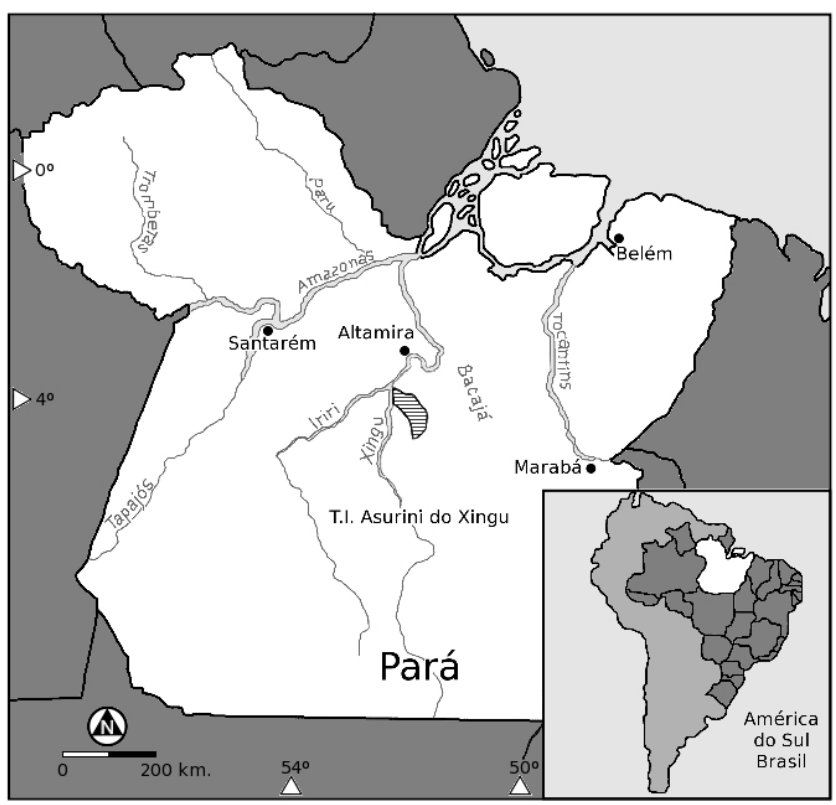

Figura 1 - Mapa de localização da terra indígena Asurini.

Em termos climáticos, a T.I. Kuatinemu compreende a zona climática A (tropical chuvoso), variação tropical de monção (Am). Este tipo climático tem como principal característica a ocorrência de chuvas do tipo monção, apresentando um regime de chuvas acentuado nos meses de dezembro a maio e uma estação seca nos meses de junho a novembro (Silva et al. 2011).

De maneira geral, toda essa região está inserida no ecossistema de florestas de terra firme amazônica e, no médio Xingu, com predominância da Floresta Ombrófila Aberta, que apresenta um estrato arbustivo pouco denso, caracterizado pela presença de grandes palmeiras (como babaçu, inajá, paxiúba, bacaba), que se associam a latossolos profundos e podzólicos e lianas lenhosas (floresta de palmeiras e floresta de cipó) (Balée \& Campbell 1990).
No médio Xingu também ocorrem capoeiras antigas - florestas secundárias - localizadas em manchas de latossolos amarelo e vermelho, de textura argilo-arenosa, em terraços e platôs sobre relevo de planaltos dissecados. O dossel dessas capoeiras antigas é alto, entre 20-25m, com certa estratificação vertical e sub-bosque um pouco mais limpo, cuja presença de lianas e espécies de árvores de floresta madura é um indicativo da estabilização das condições físicas, ou regeneração da floresta.

Nessa região, as matas de babaçu e as matas de cipó são consideradas indicativas de manejo ambiental relacionado ao estabelecimento das populações Tupi-Guarani, que há muito vem sendo pauta de estudos de ecologia histórica (Balée 1989, 2000, 2013, Balée \& Campbell 1990). Na década de oitenta, Balée (2000) esteve entre os Asurini 
do Xingu e Araweté para realizar um inventário das espécies vegetais existentes nas suas terras, bem como compreender a profundidade histórica e correspondência linguística na estrutura de classificação, nomenclatura e uso dessas espécies entre as populações Tupi-Guarani.

Dessas experiências de pesquisa, originou-se a proposta de correspondência entre a área de abrangência dessas matas e a distribuição dos sítios arqueológicos e dos solos antropogênicos na região dos interflúvios Xingu-Tocantins, confirmando manejo florestal antigo, cujas práticas seriam mantidas entre as populações Asurini e Araweté. As cronologias obtidas para os sítios arqueológicos e as análises dos solos antropogênicos, nesta região, evidenciam uma longevidade de ocupação pré-colonial (Smith 1980, Kern et. al. 2003, Silva 2003, Silva et. al. 2004).

As fontes históricas, assim como, as próprias narrativas indígenas revelam que, desde o século XIX até o início da década de 1970, o território de ocupação dos Asurini compreendia as áreas de cabeceiras dos igarapés Ipiaçava, Piranhaquara e Ipixuna, entre os rios Xingu e Bacajá. De acordo com as primeiras informações históricas, datadas do final do século XIX, o local mais antigo que os Asurini ocuparam teria sido às margens do alto rio Bacajá, de onde se deslocaram para as proximidades do rio Xingu devido às pressões dos extrativistas regionais e dos ataques dos Kayapó (Coudreau 1977, Nimuendajú 1948).

Conforme a memória dos Asurini, a ocupação da região dos igarapés Piranhaquara e Ipiaçava ocorreu desde a década de 1930, com o estabelecimento de várias aldeias e perdurou até eles serem novamente atacados pelos Kayapó - por volta dos anos 1950 - e forçados a se deslocar para a região do igarapé Ipixuna, na atual T.I. Araweté. Eles permaneceram nessa região até serem expulsos pelos Araweté que para lá se deslocaram - no final da década de 1950 - empurrados pelos Kayapó e Parakanã.

Então, os Asurini retornaram ao igarapé Ipiaçava, onde se fixaram e se dispersaram em pequenos grupos constituídos de parentes e agregados. Diante da situação de perigo eminente e já debilitados pelas perdas populacionais que vinham sofrendo ao longo dos anos, os Asurini finalmente optaram pelo contato com os brancos, acreditando ser esta uma solução para evitar o seu extermínio (Muller 1984/1985, 1990, Ribeiro 1982, Viveiros de Castro 1986, Fausto 2001).

Assim, em 1971, os Asurini do Xingu foram contatados oficialmente, primeiramente, pelos padres Anton e Karl Lukesch e, posteriormente, pela FUNAI, a partir da frente de atração liderada por Antônio Cotrim Soares (Lukesch 1976). Logo após o contato, a população Asurini fixou-se na aldeia Akapepugĩ às margens do igarapé Ipiaçava. Este assentamento perdurou até 1972, quando passaram a ocupar a aldeia Kuatinemu, no mesmo igarapé onde permaneceram até 1985, quando se transferiram para a atual aldeia Kuatinemu, às margens do Xingu (Muller 1984/1985, 1987, 1990). Em 2011, de- 
pois de quarenta anos de contato, uma parte da população mudou-se para uma nova aldeia no rio Xingu, denominada Itaaka, no extremo norte da T.I. Kuatinemu (Silva 2013).

O conhecimento dos Asurini sobre a paisagem da T.I. Kuatinemu pode ser conferido através dos lugares nome- ados. O Quadro 1 mostra os lugares conhecidos e nomeados (como aldeias, caminhos, igarapés), coletados por Müller (1990:38-40) em meados da década de 1970, revelando lugares ocupados ou transitados ao longo do século XX, na área dos igarapés Ipiaçava, Piranhaquara e Ipixuna.

\section{Quadro 1}

Listagem dos lugares significativos na memória dos Asurini do Xingu

\begin{tabular}{|c|c|c|}
\hline Lugar & Igarapés (secundários) & Igarapé \\
\hline Aldeia Ipearú & Ipekí & Piranhaquara \\
\hline Aldeia Petyma'ava & Ipikuí (margem) & Piranhaquara \\
\hline Aldeia Evuí pevi & Tapyipiri (nas proximidades) & Piranhaquara \\
\hline Aldeia Japiiva & Ykanhy (nas proximidades) & Piranhaquara \\
\hline Aldeia Mariryvoho & Tupaví (nas proximidades) & Piranhaquara \\
\hline Aldeia Muyryna & Tuí jipava & Piranhaquara \\
\hline Aldeia ysipisingoho & Arapoiava (nas proximidades) & Piranhaquara \\
\hline Várias aldeias & $\begin{array}{l}\text { Ipium yh (nome Asurini do } \\
\text { igarapé Piranhaquara) }\end{array}$ & Piranhaquara \\
\hline Lugar/caminho & Ukandú parateí & Piranhaquara \\
\hline Lugar/caminho & Jotaí & Piranhaquara \\
\hline Lugar/caminho & Jeo'ym & Piranhaquara \\
\hline Lugar/caminho & Uruvatuu & Piranhaquara \\
\hline Lugar/caminho & Jaopina & Piranhaquara \\
\hline Lugar/caminho & Piraapava & Piranhaquara \\
\hline Lugar/caminho & Kumavafuaí & Piranhaquara \\
\hline
\end{tabular}




\begin{tabular}{|c|c|c|}
\hline Várias aldeias & Kafuifuruk (margem esquerda) & Ipiaçava \\
\hline Aldeia Yvyra aka & Bykorapyykava (margem direita) & Ipiaçava \\
\hline Aldeia Yvyra aka & Yvyrapeavuí (margem direita) & Ipiaçava \\
\hline Lugar/caminho & Fundanhynga (margem esquerda) & Ipiaçava \\
\hline Lugar/caminho & Tukumarí (margem esquerda) & Ipiaçava \\
\hline Lugar/caminho & Uruiví (margem esquerda) & Ipiaçava \\
\hline Lugar/caminho & Jesiva-manhynha(margem esquerda) & Ipiaçava \\
\hline Lugar/caminho & Uaropyatyva (margem esquerda) & Ipiaçava \\
\hline Lugar/caminho & Uamirifukú (margem esquerda) & Ipiaçava \\
\hline Lugar/caminho & Turenhynha (margem esquerda) & Ipiaçava \\
\hline Lugar/caminho & Ehiraiava (margem esquerda) & Ipiaçava \\
\hline Lugar/caminho & Kumandoivoho (margem esquerda) & Ipiaçava \\
\hline Lugar/caminho & Jysingí (margem direita) & Ipiaçava \\
\hline Lugar/caminho & Utuvií (margem direita) & Ipiaçava \\
\hline Lugar/caminho & Javosivava (margem direita) & Ipiaçava \\
\hline Lugar/caminho & Mytuí (margem direita) & Ipiaçava \\
\hline Lugar/caminho & Tajahoparí (formador do Ipiaçava) & Ipiaçava \\
\hline Lugar/caminho & Ipirasisinga (formador do Ipiaçava) & Ipiaçava \\
\hline Aldeias antigas & Tekarapô (margem direita) & Ipixuna \\
\hline Aldeias antigas & Tapepirinyna (margem direita) & Ipixuna \\
\hline Aldeia Ipeivakaí & Tekarapô ou Tapepirinyna & Ipixuna \\
\hline Aldeia Paperendí & Ipihauyh (=Ipixuna, margem direita) & Ipixuna \\
\hline Aldeia Javarakapeona & Tapepirinyna e Tajahomopava (Foz) & Ipixuna \\
\hline
\end{tabular}




\begin{tabular}{|c|c|c|}
\hline Aldeia Ararondiva & Yarapava (margem esquerda) & Ipixuna \\
\hline Aldeia Ita aka & Yarapava (margem esquerda) & Ipixuna \\
\hline Aldeia Sivasingí & Tukumayava (margem esquerda) & Ipixuna \\
\hline Aldeia Javosí & Urukuavy (margem esquerda) & Ipixuna \\
\hline Aldeia Pefukuí & Urukuavy (margem esquerda) & Ipixuna \\
\hline Aldeia Kapak hakuku & Urukuavy (margem esquerda) & Ipixuna \\
\hline Aldeia Ôopsingiyh & Urukuavy (margem esquerda) & Ipixuna \\
\hline Aldeia Yvypypefukú & Urukuavy (margem esquerda) & Ipixuna \\
\hline Lugar/caminho & Takurendí (margem direita) & Ipixuna \\
\hline Lugar/caminho & Ipiataanha (formador do Ipixuna) & Ipixuna \\
\hline Lugar/caminho & Ipareym (formador do Ipixuna) & Ipixuna \\
\hline Lugar/caminho & Apirundava (margem esquerda) & Ipixuna \\
\hline Lugar/caminho & Amoaava (margem esquerda) & Ipixuna \\
\hline Lugar/caminho & Uruvuy & Ipixuna \\
\hline Lugar/caminho & Tukunareyh & Ipixuna \\
\hline Lugar/caminho & Maritaoho & Ipixuna \\
\hline Lugar/caminho & Auarabe & Ipixuna \\
\hline Lugar/caminho & Arapesingí & Ipixuna \\
\hline Lugar/caminho & Tapikwauarí (Igarapé Bom Jardim?) & Ipixuna \\
\hline
\end{tabular}

Como se pode observar no Quadro 1 , os Asurini viviam e transitavam por um território que já era conhecido por eles de longa data. Cabe ressaltar que muitos destes lugares ainda são lembrados pelos velhos até hoje. Segundo eles, isto é uma demonstra- ção de que antes do contato com os brancos eles eram muito numerosos e tinham muitas aldeias. Durante a pesquisa, ao longo dos igarapés Ipiaçava e Piranhaquara, foram localizados 6 desses antigos assentamentos (Figura 2). 
SíTIOS ARQUEOLÓGICOS NA T. I. KOATINEMO, ALTAMIRA E SENADOR JOSÉ PORFÍRIO - PA

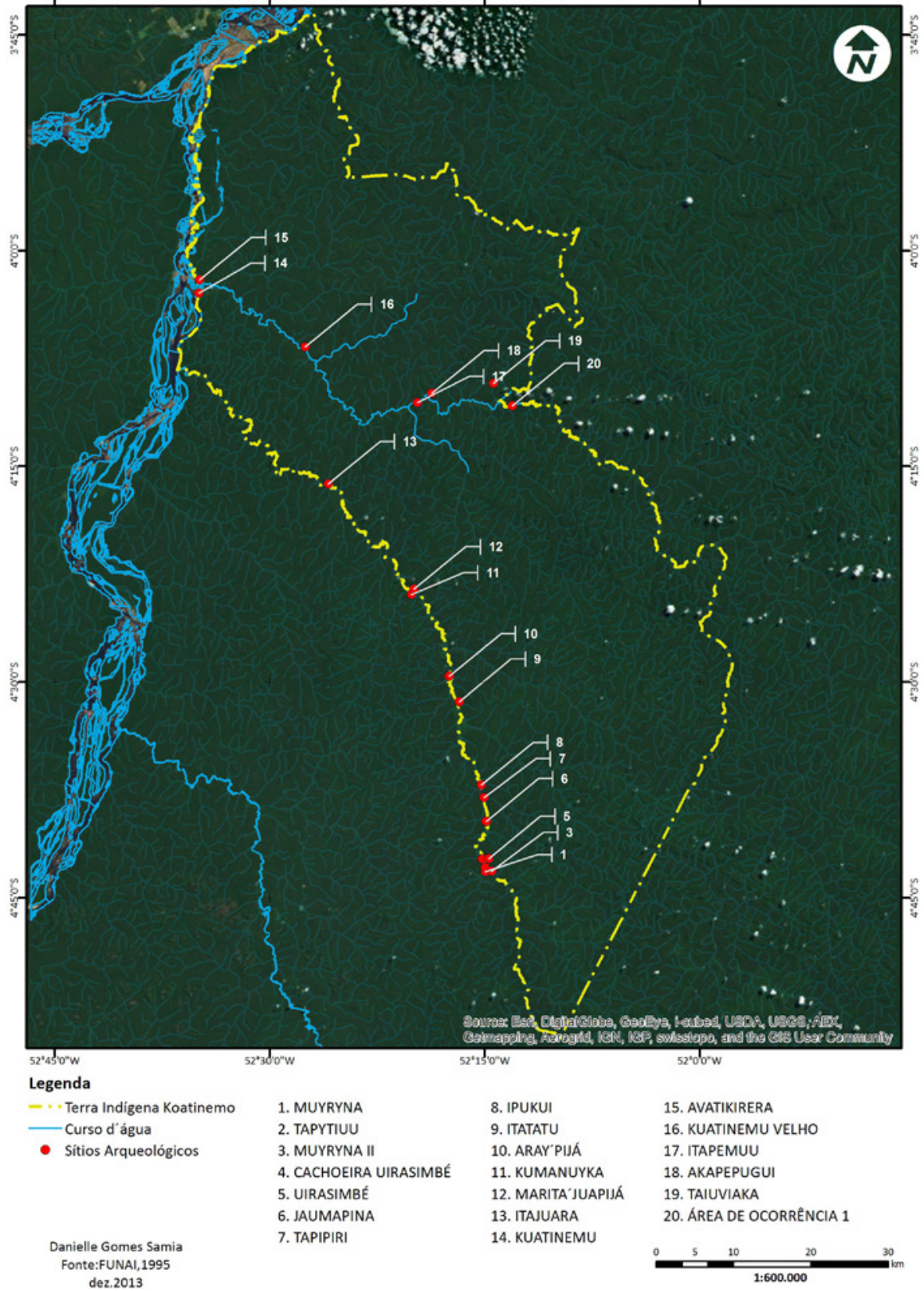

Figura 2 - Mapa de localização dos sítios arqueológicos na T.I. Kuatinemu 


\section{A PESQUISA DE CAMPO}

A pesquisa de campo foi realizada com base em métodos e técnicas de survey arqueológico (Banning 2002), adaptados ao contexto de floresta tropical. Foi realizado um survey oportunístico e probabilístico subindo $140 \mathrm{~km}$ ao longo do igarapé Piranhaquara, afluente da margem direita do rio Xingu. É importante salientar que a realização de survey em áreas florestadas implica em métodos de inspeção para a localização de vestígios arqueológicos que levem em consideração dois principais fatores: visibilidade e acessibilidade.

A T.I. Kuatinemu apresenta densa cobertura vegetal. Contudo, a pesquisa não foi substancialmente afetada por este fator, considerando que todos os lugares onde foram detectados sítios arqueológicos e antigas aldeias estavam situados em áreas de antigo manejo humano que proporcionavam boa visibilidade para a abordagem arqueológica.

Do ponto de vista da acessibilidade, o igarapé Piranhaquara apresenta um canal fluvial que oscila entre trechos mais largos e profundos de boa navegabilidade na área da foz e em alguns trechos intermediários. No entanto, a maior parte da sua extensão apresenta trechos estreitos, com muitos igapós de mata fechada sobre o canal fluvial, com afloramentos rochosos e extensos leitos cobertos com seixos, tornando a navegação difícil, especialmente no médio curso e mais perto das cabeceiras. É preciso destacar que a navegabilidade varia com as estações do ano, o que determinou o cronograma da pesquisa.

No final da estação chuvosa e início da estação seca (abril-maio), o acesso a montante do igarapé só é possível com embarcações de até cinco metros com motor de rabeta. Por isso, a pesquisa foi realizada em maio e precisamos controlar diariamente o regime de vazão das águas, pois havia risco de certo trechos ficarem muito rasos, impedindo a navegação no retorno da viagem. Foi necessário estabelecer um cronograma muito preciso para localizar as aldeias e fazer as intervenções arqueológicas.

Além disso, durante o percurso os afloramentos e os extensos leitos de seixos precisaram ser cuidadosamente contornados pelas embarcações e, por diversas vezes, foi necessário desembarcar e rebocar as canoas. Os "pedrais" são pontos de referências para os Asurini, transformados em atracadouro das canoas, locais para banho, lavagem das roupas, limpeza da caça, dos peixes e das atividades de cozinha. Nos pedrais também estão as oficinas líticas, consideradas pelos Asurini como as marcas dos seus demiurgos (Silva 2002).

A época intermediária entre as estações chuvosa e seca é a melhor para a realização deste tipo de pesquisa. No auge da estação chuvosa, o volume de chuvas dificulta a pesquisa e na estação seca a escassez de água torna inviável a navegação de vários trechos (Figura 3). 


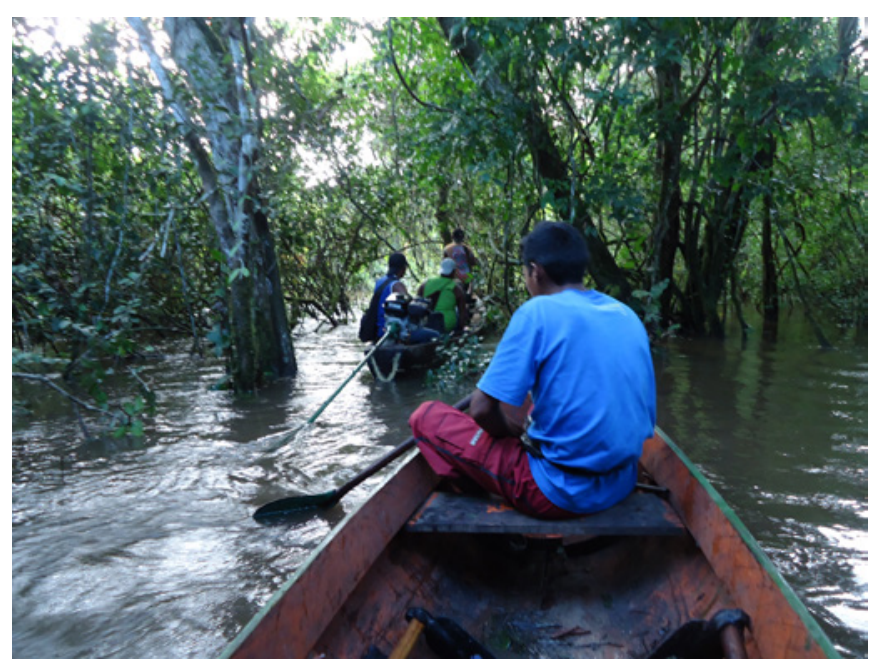

Figura 3 - O deslocamento pelo igarapé Piranhaquara

Considerando as condições de visibilidade e acessibilidade da área de pesquisa e que os Asurini não a percorriam há muitos anos, os procedimentos do survey foram adaptados para:

1) a inspeção visual das áreas pesquisadas, tendo como referência geográfica o igarapé Piranhaquara, a partir do deslocamento embarcado e à pé;

2) a estratégia de localização dos assentamentos antigos Asurini e demais sítios arqueológicos foi oportunística e probalilística, considerando a indicação dos Asurini sobre as áreas manejadas e os locais das antigas aldeias;

3) os arqueólogos também realizaram de forma independente dos Asurini as inspeções visuais nos acampamentos de caça, pesca e repouso utilizados na subida do igarapé;

4) os caminhamentos para a identificação de elementos paisagísticos e localização dos sítios, bem como a coleta do material de superfície e as sondagens - poços-teste de $50 \mathrm{~cm}$ x $50 \mathrm{~cm}$ e shovel testing - não foram realizados em transects, mas de forma aleatória e pontual.

Com a cobertura parcial das áreas pesquisadas, considerando que a logística de campo não possibilitava tempo hábil para delimitar a extensão dos sítios em termos da profundidade e dispersão do material arqueológico, adotou-se uma perspectiva amostral abrangente da área de estudo, tanto em termos de superfície como de sub-superfície. A prioridade era localizar as antigas aldeias Asurini e realizar amostragens aleatórias e pontuais do material histórico/arqueológico para elaborar um diagnóstico arqueológico da ocupação na área. E, por tratar-se de uma pesquisa colaborativa, os Asurini:

1) participaram na elaboração da proposta e definição da logística da pesquisa. 
2) foram os responsáveis pela dinâmica da pesquisa, definindo os percursos a serem percorridos diariamente, escolhendo os locais de acampamento e indicando a localização dos sítios a serem investigados.

3) tomaram decisões e atuaram no levantamento do potencial arqueológico da área e na logística da expedição.

4) indicaram os locais possíveis de serem prospectados nas antigas aldeias a partir do seu conhecimento sobre a distribuição das antigas áreas de atividades e estruturas domésticas e coletivas.

5) decidiram sobre retirar ou não retirar os materiais arqueológicos Asurini mais significativos.

6) definiram quais objetos arqueológicos permaneceriam na T.I. para serem guardados nas escolas ou em suas casas.

No trabalho de identificação das antigas aldeias e acampamentos Asurini, os velhos se ocuparam de indicar a localização e de mostrar aos jovens as marcas que confirmavam a existência desses antigos locais de ocupação (vegetação secundária/capoeiras, terra preta, antigas picadas na mata, vestígios de esteios da tavyva ${ }^{1}$, cerâmica, material lítico, cemitérios). Os jovens se ocuparam de realizar o trabalho pesado (como abrir picadas na mata, desobstruir a passagem das canoas, montar os acampamentos, conseguir e processar alimento), aprender a lidar com os equipamentos (como GPS, bússola, ferramen- tas de escavação), coletar o material histórico/arqueológico e traduzir as informações dos velhos não bilíngues sobre os locais de ocupação e materiais históricos/arqueológicos (Figura 4).

Outro aspecto importante, que precisou ser levado em consideração durante a tomada de decisões sobre os procedimentos metodológicos a serem realizados na pesquisa arqueológica, foi a quantidade de pessoas que foram na expedição. Como foram 98 pessoas (homens, mulheres, jovens e crianças entre 2 meses e 85 anos de idade) foi imprescindível regular as atividades da pesquisa com a dinâmica dos acampamentos, com a obtenção de alimentos (caça e pesca), com os eventuais problemas de saúde, os conflitos interpessoais, os ânimos e desânimos para o trabalho.

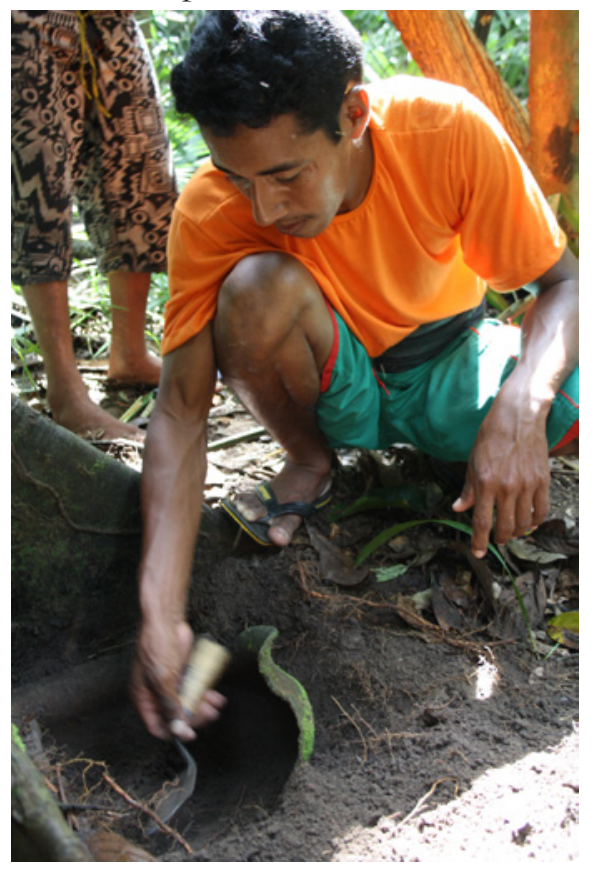

Figura 4 - Prospecção na aldeia Tapipiri 
Durante a pesquisa, foram montados sete acampamentos para descanso, alimentação e planejamento das atividades subsequentes. No Quadro 2, apresentamos os acampamentos e suas posições georreferenciadas. Chamamos a atenção para o fato de que a maioria deles coincide ou es-

Quadro 2

Localização dos acampamentos no igarapé Piranhaquara (maio 2013)

\begin{tabular}{c|c|c}
\hline Acampamento & Localização & Permanência \\
\hline Acampamento 1 & $22 \mathrm{M} 341100$ E9527826N & pernoite 07 a 08/05/2013 \\
\hline Acampamento 2 & $22 \mathrm{M} 352356$ E9513946N & um dia e duas noites 08 a $10 / 05 / 2013$ \\
\hline Acampamento 3 & $22 \mathrm{M} 356733$ E9503214N & um dia e duas noites 10 a $12 / 05 / 2013$ \\
\hline Acampamento 4 & $22 \mathrm{M} 357997$ E9495442N & um dia duas noites 12 a $14 / 05 / 2013$ \\
\hline Acampamento 5 & $22 \mathrm{M} 361573$ E9484652N & um dia duas noites 14 a $16 / 05 / 2013$ \\
\hline Acampamento 6 & $22 \mathrm{M} \mathrm{360660} \mathrm{E9489486N}$ & pernoite 16 a $17 / 05 / 2013$ \\
\hline Acampamento 7 & $22 \mathrm{M} 361286$ E9479720N & três dias e quatro noites 17 a $21 / 05 / 2013$ \\
\hline
\end{tabular}

No dia 21/05/2013 iniciamos o trajeto de retorno para a Aldeia Kuatinemu, onde chegamos no $\operatorname{dia} 22 / 05 / 2013$.

\section{RESULTADOS DA PESQUISA AR-} QUEOLÓGICA

Durante o levantamento arqueológico no igarapé Piranhaquara, identificamos 13 sítios arqueológicos, dos quais 4 são antigas aldeias Asurini. Na descrição abaixo, será possível verificar que todos estão localizados em áreas com evidências de manejo florestal (tais como florestas de palmeiras e cipós, capoeiras antigas, roças, manchas de terra preta). Além disso, os sítios arqueológicos não-Asurini foram quase todos loca- tão próximos dos locais onde foram identificados os sítios arqueológicos e áreas de caça e pesca dos Asurini e Araweté. Este quadro também demonstra o ritmo da pesquisa que, em grande parte, foi resultante da dinâmica de vazão das águas do igarapé Piranhaquara. 
eles se localizavam em topos de morro, ramentos rochosos no igarapé e quase colinas e nos terraços fluviais. As ofici- sempre nas proximidades de outro sínas líticas estavam localizadas nos aflo- tio arqueológico.

Quadro 3

Sítios arqueológicos no igarapé Piranhaquara

\begin{tabular}{|c|c|c|c|c|c|c|}
\hline $\begin{array}{c}\text { Sítios } \\
\text { arqueológicos }\end{array}$ & Sigla & Coordenadas & $\begin{array}{c}\text { Bacia hidrográfica e } \\
\text { drenagem mais próxima }\end{array}$ & $\begin{array}{l}\text { Implan- } \\
\text { tação }\end{array}$ & Prof. & TPA \\
\hline Itajuara & PA-KTM-07 & 22M341085E9527838N & $\begin{array}{l}\text { Margem esquerda do Iga- } \\
\text { rapé Piranhaquara, Xingu }\end{array}$ & $\begin{array}{l}\text { Topo de } \\
\text { colina }\end{array}$ & SI & $\mathrm{NI}$ \\
\hline Maritaiva'pijá & PA-KTM-08 & 22M352066E9513992N & $\begin{array}{l}\text { Margem direita do Igarapé } \\
\text { Piranhaquara, Xingu }\end{array}$ & $\begin{array}{l}\text { Topo de } \\
\text { morro }\end{array}$ & $40 \mathrm{~cm}$ & $\mathrm{P}$ \\
\hline Kumanuyka & PA-KTM-09 & 22M351839E9513792N & $\begin{array}{l}\text { Margem esquerda do Iga- } \\
\text { rapé Piranhaquara, Xingu }\end{array}$ & $\begin{array}{l}\text { Topo de } \\
\text { morro }\end{array}$ & $40 \mathrm{~cm}$ & $\mathrm{P}$ \\
\hline Araypijá & PA-KTM-10 & 22M356733E9503214N & $\begin{array}{l}\text { Margem esquerda do Iga- } \\
\text { rapé Piranhaquara, Xingu }\end{array}$ & $\begin{array}{l}\text { Topo de } \\
\text { morro }\end{array}$ & $50 \mathrm{~cm}$ & $\mathrm{P}$ \\
\hline Itatatu & PA-KTM-11 & 22M358041E9499978N & $\begin{array}{c}\text { Margem direita do Igarapé } \\
\text { Piranhaquara, Xingu }\end{array}$ & $\begin{array}{l}\text { Topo de } \\
\text { morro }\end{array}$ & SI & NI \\
\hline Araypijá & PA-KTM-12 & 22M361573E $9484652 \mathrm{~N}$ & $\begin{array}{l}\text { Margem esquerda do Iga- } \\
\text { rapé Piranhaquara, Xingu }\end{array}$ & $\begin{array}{l}\text { Topo de } \\
\text { morro }\end{array}$ & $30 \mathrm{~cm}$ & $\mathrm{P}$ \\
\hline $\begin{array}{c}\text { Ipukui } \\
\text { (aldeia antiga) }\end{array}$ & PA-KTM-13 & 22M360915E $9489302 \mathrm{~N}$ & $\begin{array}{l}\text { Margem direita do Igarapé } \\
\text { Piranhaquara, Xingu }\end{array}$ & Terraço & CS & $\mathrm{P}$ \\
\hline $\begin{array}{c}\text { Tapypiri } \\
\text { (aldeia antiga) }\end{array}$ & PA-KTM-14 & 22M361269E9487684N & $\begin{array}{l}\text { Margem direita do Igarapé } \\
\text { Piranhaquara, Xingu }\end{array}$ & Terraço & CS & $\mathrm{P}$ \\
\hline Uirasimbé & PA-KTM-15 & 22M361320E9479632N & $\begin{array}{l}\text { Margem direita do Igarapé } \\
\text { Piranhaquara, Xingu }\end{array}$ & Terraço & CS & $\mathrm{P}$ \\
\hline $\begin{array}{l}\text { Cachoeira } \\
\text { Uirasimbé }\end{array}$ & PA-KTM-16 & 22M361232E $9479624 \mathrm{~N}$ & $\begin{array}{l}\text { Margem esquerda do Iga- } \\
\text { rapé Piranhaquara, Xingu }\end{array}$ & $\begin{array}{c}\text { Coroa de } \\
\text { pedra }\end{array}$ & SUP. & NA \\
\hline $\begin{array}{c}\text { Myrina } \\
\text { (aldeia antiga) }\end{array}$ & PA-KTM-17 & 22M361765E9478590N & $\begin{array}{l}\text { Margem direita do Igarapé } \\
\text { Piranhaquara, Xingu }\end{array}$ & $\begin{array}{l}\text { Topo de } \\
\text { colina }\end{array}$ & $30 \mathrm{~cm}$ & $\mathrm{P}$ \\
\hline Myrina II & PA-KTM-18 & $22 \mathrm{M} 361572 \mathrm{E} 9478460 \mathrm{~N}$ & $\begin{array}{c}\text { Curso do Igarapé } \\
\text { Piranhaquara, Xingu }\end{array}$ & $\begin{array}{c}\text { Coroa de } \\
\text { pedra }\end{array}$ & SUP. & NA \\
\hline $\begin{array}{c}\text { Typytiuu } \\
\text { (aldeia antiga) }\end{array}$ & PA-KTM-19 & $22 \mathrm{M} 361572 \mathrm{E} 9478460 \mathrm{~N}$ & $\begin{array}{l}\text { Margem direita do Igarapé } \\
\text { Piranhaquara, Xingu }\end{array}$ & Terraço & $60 \mathrm{~cm}$ & $\mathrm{P}$ \\
\hline $\begin{array}{l}\text { Itaaka } \\
\text { (aldeia atual) }\end{array}$ & PA-KTM-20 & 22M326490E9581388N & Margem direita do Xingu & $\begin{array}{l}\text { Topo de } \\
\text { morro }\end{array}$ & SI & $\mathrm{P}$ \\
\hline
\end{tabular}

Legenda: P: presença de terra-preta arqueológica/ NI: não identificado/ NA: não se aplica/SI: sem intervenção/CS: coleta superfície 


\section{SÍTIO ITAJUARA (PA-KTM-07)}

O sítio Itajuara está localizado nas coordenadas 22M 341085E 9527838N na margem esquerda do igarapé Piranhaquara. Ele possui boas condições de acesso por água, pois está situado em trecho de maior navegabilidade do igarapé. Ele está implantado em um topo de colina. Parte da paisagem atual do sítio Itajuara é composta por mata secundária, com concentração de palmeiras de babaçu. Durante o caminhamento no local, foram identificados fragmentos de cerâmica em superfície e observada a presença de uma oficina lítica sobre um pedral adjacente ao sítio. Os Asurini já conheciam o lugar, que era utilizado como acampamento durante as suas incursões pelo igarapé. Não foram realizadas intervenções arqueológicas ou coleta de material.

\section{MARITAIVA'PIJÁ (PA-KTM-08)}

O sítio Maritaiva'pijá está localizado nas coordenadas 22M 352066E 9513992N, na margem esquerda do igarapé Piranhaquara. O sítio encontra-se implantado em topo de morro, circundado pelo igarapé nas faces leste e sul. A vegetação do sítio é composta por mata secundária em estado avançado de regeneração, com matas de cipó e árvores de grande porte. Durante o caminhamento no local, foi possível observar manchas de terra preta e material arqueológico em superfície. Foram realizadas coletas de material arqueológico em superfície e sub-superfície em uma profundidade de $50 \mathrm{~cm}$.

\section{KUMANUYKA (PA-KTM-09)}

O sítio está localizado nas coordenadas 22M 351839E 9513792N, na margem direita do igarapé Piranhaquara. O sítio está implantado em topo de morro e apresenta uma vegetação composta primordialmente por mata secundária com palmeiras babaçu e roça de 'pau-preto' que, segundo os Asurini, é utilizado como lenha. Durante o caminhamento no local, foi possível observar manchas de terra preta e material arqueológico em superfície (cerâmica e lítico). Foram realizadas coletas de material arqueológico em superfície e sub-superfície. Segundo os Asurini, o material arqueológico coletado neste sítio era de seus antepassados.

\section{ARAYPIJÁ (PA-KTM-10)}

O sítio Araypijá está localizado nas coordenadas 22M 356733E 9503214N, na margem esquerda do igarapé Piranhaquara. O sítio está implantado em topo de morro, alta vertente, circundado pelo igarapé em sua face leste e por igapó que o cerca em suas faces norte e parte da face oeste. A paisagem do sítio é composta por mata secundária em estado avançado de regeneração. No topo do morro e na alta vertente, podem ser observadas concentrações de material arqueológico em superfície. Durante o caminhamento no sítio, foi possível observar manchas de terra preta e material arqueológico em superfície. Foram realizadas coletas de material em superfície e sub-superfície. Os Asurini reconheceram parte do material cerâmico como pertencente aos seus antepassados e o restante como 
pertencente à Anumaí, um personagem mítico que integra a sua cosmologia (Silva 2002).

\section{ITATATU (PA-KTM- 11$)$}

O sítio Itatatu está localizado nas coordenadas 22M 358041E 9499978N, na margem direita do igarapé Piranhaquara. O sítio está implantado sobre um topo de morro e suas vertentes estão cobertas por afloramento de quartzo leitoso/hialino. Devido a essa característica, Takamui Asurini referiu-se a este local como Itatinga (pedra branca). Trata-se de um antigo acampamento Asurini denominado "acampamento da anta", onde se observa a presença de materiais industrializados (como pilhas, cartuchos de munição, plásticos, embalagens de remédio e embalagens de óleo combustível). Neste sítio, foram identificados materiais líticos e fragmentos cerâmicos. Não foram realizadas intervenções ou coletas de material arqueológico.

\section{JAUNAPINA (PA-KTM-12)}

O sítio arqueológico Jaunapina está localizado nas coordenadas 22M $361573 \mathrm{E} 9484652 \mathrm{~N}$, na margem direita do igarapé Piranhaquara. O sítio encontra-se implantado em terraço não inundável e apresenta vegetação caracterizada por mata secundária, capoeira antiga com concentração de palmeiras açaí, nas proximidades do igarapé. O local foi uma antiga roça Asurini e onde nasceu uma mulher Asurini. No, sítio foram identificadas manchas de terra preta e material arqueológico em superfície. Foram realizadas coletas de material arqueológico em superfície e sub-superfície.

\section{IPUKUI (PA-KTM-13)}

O sítio está localizado nas coordenadas 22M 360915E 9489302N, na margem direita do igarapé Piranhaquara. Ele se encontra implantado em terraço não inundável do igarapé Piranhanquara, em área de mata secundária, composta por capoeira, com palmeiras, cipós, pau-de-lenha (iagyva na língua Asurini) e árvores frutíferas (taperebá, Spondias mombin). Na margem do igarapé, junto ao sítio, há um pedral com uma oficina lítica. No sítio, foi possível observar manchas de terra preta e material arqueológico em superfície. Trata-se de uma antiga aldeia Asurini que está sobre uma ocupação pretérita não-Asurini. Foram realizadas coletas de material arqueológico em superfície e sub-superfície. Os Asurini reconheceram o local da Tavyva, bem como a cerâmica de seus antepassados.

\section{TAPYPIRI (PA-KTM- 14)}

O sítio Tapypiri está localizado nas coordenadas 22M 361269E 9487684N, na margem direita do igarapé Piranhaquara, em terraço não inundável do igarapé. A vegetação é caracterizada por mata secundária (como a capoeira, concentração de palmeiras de babaçu). Foram realizados caminhamentos assistemáticos e coletas de superfície e sub-superfície aleatórias e/ou pontuais. Trata-se de uma antiga aldeia Asurini e nela observamos manchas de terra preta e grande concentração de vestígios cerâmicos Asurini e não- 
-Asurini. Ela está associada a uma oficina lítica que fica em um afloramento rochoso nas margens do igarapé. Os Asurini fizeram o reconhecimento dos esteios da tavyva, que estavam alinhados na direção norte-sul. Eles também reconheceram as vasilhas cerâmicas como sendo de seus antepassados e, inclusive, resgataram várias delas ainda inteiras.

\section{UIRASIMBÉ (PA-KTM-15)}

O sítio arqueológico Uirasimbé está localizado nas coordenadas 22M 361320E 9479632N na margem direita do igarapé Piranhaquara. O sítio está implantado em terraço não inundável do igarapé, sendo circundado por este em suas faces norte e leste e cercado por corredeiras. O sítio apresenta manchas de terra preta e concentrações de material cerâmico em superfície. A vegetação é caracterizada por mata secundária (como as palmeiras). Este sítio fica próximo à antiga aldeia Myrina e, segundo os Asurini, era um local de caça e de coleta do babaçu. Foi realizada uma coleta de poucos fragmentos de cerâmica em superfície. Para Moreyra Asurini, a cerâmica deste sítio teria sido produzida pelos antepassados dos Asurini. Havia, inclusive, um grande fragmento cerâmico que os Asurini atribuíram a grande vasilha ritual (tawva rukaia). Ela teria sido deslocada para aquele local pelos Kayapó, no tempo em que eles guerreavam com os Asurini e saqueavam as aldeias abandonadas.

\section{CACHOEIRA UIRASIMBÉ (PA-KTM-16)}

O sítio arqueológico Cachoeira Uirasimbé está localizado nas coordenadas
22M 361232E 9479624N, na margem esquerda do igarapé Piranhaquara. Trata-se de uma oficina lítica composta por 22 feições circulares e elípticas de polidores e afiadores fixos, medindo entre 10 e $30 \mathrm{~cm}$ no eixo maior; $5 \mathrm{~cm}$ e 25 no eixo menor; entre $1,5 \mathrm{~cm}$ a $4,0 \mathrm{~cm}$ de profundidade. Foram tiradas fotografias e foi feito croqui esquemático da distribuição dos polidores e afiadores.

\section{MYRINA (PA-KTM-17)}

O sítio Myrina está localizado nas coordenadas 22M 361765E $9478590 \mathrm{~N}$, na margem direita do igarapé Piranhaquara. O sítio encontra-se implantado em topo de colina com inclinação suave, cercado na face nordeste por um pequeno igarapé onde há concentração de palmeiras açaí. O sítio está inserido em uma área de mata secundária. No entorno do sítio, há corredeiras e afloramentos rochosos onde aparecem oficinas líticas com afiadores e polidores fixos. Trata-se de uma antiga aldeia Asurini que apresenta também vestígios de uma ocupação não-Asurini. No sítio, pode-se observar manchas de terra preta, concentrações de fragmentos cerâmicos, artefatos líticos e marcas da antiga ocupação Asurini (com árvores cortadas, esteios da tavyva, vasilhas cerâmicas inteiras). Foram realizadas coletas de superfície e sub-superfície e uma prospecção $(50 \mathrm{~cm}$ x $50 \mathrm{~cm}) \mathrm{com}$ coleta de solo para datação e análise geoquímica.

\section{MYRINA II (PA-KTM-18)}

O sítio Myrina II está localizado nas coordenadas 22M 361572E $9478460 \mathrm{~N}$, 
em um afloramento rochoso no igarapé Piranhaquara. Foi realizado o registro fotográfico dos conjuntos de afiadores e amoladores.

\section{TYPYTIUÚ (PA-KTM-19)}

O sítio Typytiuu está localizado nas coordenadas 22M 361572E 9478460N, na margem esquerda do igarapé Piranhaquara. $\mathrm{O}$ sítio está implantado no terraço não inundável do igarapé e apresenta uma vegetação característica de mata secundária (como palmeiras, cuieiras, árvores de médio e grande porte e cipós). Trata-se de uma antiga aldeia Asurini que está associada com uma oficina lítica. Os Asurini localizaram os esteios da tavyva e nós pudemos identificar manchas de terra preta, áreas de lixeiras em forma de montículos e concentrações de material cerâmico Asurini e não-Asurini. Foram realizados caminhamentos aleatórios e coletas de superfície e sub-superfície aleatórias e/ou pontuais.

\section{ITAAKA (PA-KTM-20)}

O sítio está localizado nas coordenadas 22M 326490E 9581388N, na margem direita do médio Xingu. Trata-se de uma nova aldeia atual Asurini que foi implantada por um grupo doméstico, no ano de 2011. Ela está situada na alta e média vertente de um topo de morro sobre um sítio arqueológico de ocupação não-Asurini. O topo do morro é coberto por floresta regenerada, pois o local já havia sido utilizado como roça. Neste sítio, pode-se observar a presença de terra preta e grande concentração de fragmentos cerâmicos em superfície em associação com materiais líticos. Nesse sítio não foram realizadas intervenções arqueológicas. Escavamos este sítio em agosto de 2014, mas os dados ainda não foram processados.

\section{PAISAGEM E MEMÓRIA NA T.I. KUATINEMU}

$\mathrm{Na}$ pesquisa arqueológica, o termo paisagem vem sendo empregado conforme diferentes perspectivas para entender a vida das populações humanas na sua interrelação com o ambiente, ao longo do tempo. Assim, desde os anos de 1970 já se utilizava a designação "arqueologia da paisagem" para assinalar trabalhos que tratavam, por exemplo, 1) da distribuição locacional dos sítios, 2) das estratégias econômicas e suas dinâmicas inter-regionais, 3) dos determinantes econômicos dos padrões de assentamentos, 4) das potencialidades e limitações ambientais para a definição das estratégias de subsistência e seus impactos no meio ambiente, 5) dos processos demográficos e de complexificação social e suas relações com as configurações ambientais regionais, 6) das matérias-primas, das características e distribuições artefatuais.

De fato, o foco principal desses trabalhos era analisar e compreender as inter-relações das populações com seu ambiente físico, em termos das suas estratégias adaptativas e econômicas de subsistência e assentamento, portanto, mais afinadas com o que se costuma designar como arqueologia espacial, arqueologia ambiental e/ou ecológica do que com o que se entende atualmente como "arqueologia da pai- 
sagem" ou "arqueologia do lugar". Estas arqueologias (espacial, ambiental, ecológica) consagraram termos como padrão e sistema de assentamento, tipos de sítios, estratégias de mobilidade, padrão e sistema de subsistência etc. Ao mesmo tempo, possibilitaram tanto o refinamento das metodologias (interdisciplinares) de campo intra, inter e off site - em diferentes escalas locais e regionais - quanto o fortalecimento de campos como a geoarqueologia, a bioarqueologia e a paleoecologia, o aperfeiçoamento das análises estatísticas e das tecnologias de descrição e análise da distribuição dos sítios e materiais arqueológicos na paisagem. Neste caso, uma paisagem entendida, principalmente, como um cenário ambiental de potencialidades e/ou coerções econômicas e adaptativas (David \& Thomas 2008:28-32).

A partir do final da década de 1970 , porém, já se vislumbrava uma mudança de perspectiva sobre a paisagem, que começava a ser entendida em sua dimensão social, indo além da mera dimensão ambiental. Vários trabalhos foram realizados para compreender os processos de expansão, interação e relações de populações e de lugares em diferentes escalas regionais. Esta perspectiva se intensificou nas décadas de 1980 e 1990, especialmente, sobretudo, no que se refere aos estudos estilísticos dos objetos que buscavam compreender a relação entre conjuntos artefatuais e identidades sociais e culturais - os estudos de proveniência, de produção de objetos, de redes sociais de troca de objetos e matérias-primas e de relações comerciais exemplificam esta perspec- tiva socialmente orientada de estudos sobre a paisagem.

A adoção de uma perspectiva fenomenológica na pesquisa arqueológica sobre o tema possibilitou entender as paisagens e os sítios arqueológicos como significativos e sensorialmente apreendidos e vividos. Se em um primeiro momento, privilegiou-se as relações ecológicas, despindo as paisagens indígenas de seus significados simbólicos, em um segundo momento, ocupou-se em reconhecer os diferentes modos a partir dos quais esses povos apreendem, constroem e atribuem significados às paisagens e aos lugares (David \& Thomas 2008:34-35). Neste novo contexto, a paisagem passou a ser entendida como sendo o resultado da vivência, da experiência de habitar (dwelling) e apreendida a partir de diferentes práticas de sentido e significados (Bender 1993, Tilley 1994, Knapp \& Ashmore 1999, Bowser \& Zedeño 2008).

Nesta pesquisa, nosso objetivo como arqueólogas não era apenas investigar os testemunhos da ocupação humana na T.I. Kuatinemu, mas entender, fundamentalmente, a relação dos Asurini com os vestígios arqueológicos e seus contextos de deposição, ou seja, a partir de uma "arqueologia do presente" (Ruibal 2008) tentar entender como os Asurini vivem no presente a relação entre a paisagem, os sítios arqueológicos (antigas aldeias e sítios não-Asurini) e os objetos arqueológicos. Também queríamos apreender, como nesta vivência, a tradição oral e a memória se articulam na apreensão da T.I. Kuatinemu como um território 
que se constitui a partir da paisagem e dos seus lugares significativos (Shetler 2007, Zedeño \& Browser 2009).

Em diferentes contextos, foi observado que os povos indígenas conectam os vestígios materiais e os lugares às narrativas sobre o seu passado histórico e mítico. É a tradição oral e a memória que embasam essas narrativas, tornando-as significativas nos processos de construção de identidades e pertencimento aos lugares (Brown 2004, Carrol, Zedeño \& Stoffle 2004, Whitridge 2004, Bowser \& Zedeño 2008, Silva 2002, Silva et al. 2011). Para os Asurini, os registros arqueológicos e os lugares não falam apenas de acontecimentos no passado, mas eles também dão sentido às realidades vividas no presente. Para eles, a vivência com esses vestígios materiais e com os lugares ocupados pelos seus ancestrais na T.I. Kuatinemu possibilita a constante (re)elaboração da sua memória, tradição oral e identidade (Silva 2011, 2013, Silva et al. 2011). Como disse Ajé, um jovem Asurini:

"Mais tarde nós vamos poder contar para os nossos filhos como nossos antigos viviam, o que eles comiam, onde eles ficavam, onde eles plantavam, onde Mureyra, Tacamui, Mwaiva e todos os antigos viveram. É muito bom conhecer nossas aldeias e relembrar dos nossos antepassados, daquilo que eles fizeram, de como eles escaparam dos ataques, de como foi o encontro deles com os brancos. É muito importante conhecer o nosso passado".

A experiência junto aos Asurini nos faz recordar as palavras do arqueólo- go Paul Lane para quem "as paisagens não são estáticas, formas inscritas e convencionalmente documentadas por cartógrafos, arqueólogos e geógrafos históricos, mas são fenômenos temporais com múltiplos e, muitas vezes, sobrepostos ritmos que decorrem do processo de ocupação humana ou, em outras palavras, do estar na terra" (Lane 2008:242).

Para os Asurini, como para outros povos ameríndios, nomear lugares e atribuir a eles significados memoriais são modos de estar no tempo e fazer história. Recontar e reviver as "histórias" dos lugares e daqueles que neles viveram produz e reforça um sentimento de pertencimento a estes lugares. No caso Asurini, as narrativas (históricas, autobiográficas e míticas) estão inscritas na paisagem e promovem o estabelecimento de vínculos com a terra que eles chamam de ure yvi (nossa terra), a terra dos Asurini do Xingu. Esses vínculos, por sua vez, reforçam-se na medida em que os Asurini deixam seus rastros de vida nestas terras, seguindo aqueles de seus antepassados e ancestrais míticos. A viagem pelo Ipiaçava e Piranhaquara é um exemplo disso, pois eles revisitaram os lugares de seus antepassados e inscreveram neles suas próprias experiências, entrelaçando passado e presente.

Do ponto de vista arqueológico, os sítios identificados às margens do Piranhaquara se configuram como um palimpsesto, onde a história dos Asurini está representada nas camadas superficiais de ocupação dos sítios. De acordo com as pesquisas arqueológicas regionais, o estabelecimento das 
populações Tupi-Guarani parece ser responsável pela maior parte do registro arqueológico identificado na região do interflúvio Xingu e Tocantins. Isto parece ser totalmente condizente com os contextos arqueológicos identificados ao longo do igarapé Piranhaquara. Podemos dizer que os conjuntos cerâmicos encontrados nos sítios arqueológicos e antigas aldeias Asurini são a materialidade que faz o entrelaçamento entre as diferentes temporalidades desta paisagem e as narrativas sobre o passado, sejam elas arqueológicas ou dos próprios Asurini.

\section{PALAVRAS FINAIS}

Há alguns anos o antropólogo Tim Ingold (1993) publicou um artigo intitulado "The Temporality of Landscape", no qual procurou mostrar que a vida é um processo que envolve a passagem do tempo e, ao mesmo tempo, a formação de paisagens. A paisagem para ele seria a forma de realização (embodiment) da taskscape, que ele definiu como sendo o entrelaçamento das atividades que são constitutivas do habitar (dwelling) e cuja temporalidade é eminentemente social e reside na rede de inter-relações entre os múltiplos ritmos da vivência e que constituem a própria taskscape.

Temporalidade e historicidade, portanto, fundem-se na experiência daqueles que, em suas atividades, conduzem o processo da vida social. Logo, a paisagem seria uma construção em movimento e se constituiria como um registro duradouro de - e testemunho para - vidas e atividades de gerações pas- sadas que tenham vivido nela e assim fazendo tenham deixado alguma coisa de si mesmas nesta paisagem. Para o arqueólogo, a paisagem conta uma história na medida em que está impregnada com o passado e é preciso um engajamento com esta paisagem para que se possa apreender este passado. A experiência arqueológica seria ela própria uma experiência de dwelling (habitar) e o objeto de estudo da arqueologia seria a temporalidade das paisagens.

Diante de nossas experiências de campo junto aos Asurini, ficamos inclinadas a concordar com Ingold. Pode-se dizer que o conhecimento arqueológico se dá a partir da experiência, da vivência com o registro arqueológico e nele se incluem as paisagens. Assim, acreditamos que um dos objetivos da arqueologia é buscar o movimento das coisas supostamente estáticas que constituem o registro arqueológico. São os ritmos da vida que ela quer apreender: as paisagens do movimento e o movimento das paisagens.

\section{AGRADECIMENTOS}

Agradecemos aos Asurini do Xingu pelos ensinamentos e parceria na pesquisa. Ao Eduardo Bespalez, Meliam Viganó e Alice Vilela pela troca de ideias e participação na pesquisa de campo. A Wanda e Marcela pelo seu bom humor durante os trabalhos. Ao Francisco Noelli pela leitura do texto e sugestões. Os projetos de pesquisa que geraram este artigo foram financiados pela FAPESP: Território e História dos Asurini do Xingu. Um estudo bibliográfico, documental, arqueológico e etnoarqueológico 
sobre a trajetória histórica dos Asurini do Xingu (século XIX aos dias atuais) (Processo 2008/58278-6); Território e memória dos Asurini do Xingu: arqueologia colaborativa na T.I. Kuatinemu, Pará (Processo 2012/51312-0).

\section{NOTA}

${ }^{1}$ Casa comunal Asurini. Tava = aldeia; yva = sufixo que indica a qualidade de fazer algo existir; tavyva = aquilo que gera a aldeia.

\section{REFERÊNCIAS}

Baleé, W. 1989. The Culture of Amazonian Forests, in Resource Management in Amazonia: Indigenous and Folk Strategies - Advances in Economic Botany - Volume 7. Editado por D.A. Posey, \& W. Baleé, pp. 1-17. Bronx: New York Botanical Garden.

2000. Antiquity of tradicional ethnobiological knowledge in Amazonia: TheTupí-Guaraní family and time. Ethnobistory 47(2):399-422.

2013. Cultural Forests of the Amazon: A historical ecology of people and their landscapes. Tuscaloosa: The University of Alabama.

Balée, W., e D.G. Campbell. 1990. Ecological aspects of liana forest, Xingu River, Amazonian Brazil. Biotropica 22(1): 36-47.

Banning, E.B. 2002. Archaeological Survey. New York: Kluwer Academic/Plenum Publishers.

Bender, B. 1993. Landscape. Politics and perspectives. Oxford: Blackwell.

Brown, L.A. 2004. Dangerous places and wild spaces: creating meaning with materials and space at contemporary Maya shrines on El Duende Mountain. Journal of Archaeological Method and Theory 11(1):31-58.

Bowser, B., \& M.N. Zedeño (Eds.). 2008. The archaeology of meaningful places. Salt Lake City: The University of Utah Press.

Carrol, A.K., M. Zedeño, e R.W. Stoffle. 2004. Landscapes of the ghost dance: a cartography of Numic ritual. Journal of $A r-$ chaeological Method and Theory 11(2):127-156.

Coudreau, H. 1977. Viagem ao Xingu. São Paulo: Itatiaia/EDUSP.

David, B., \& J. Thomas. 2008. Introduction. In: Handbook of landscape archaeology. Editado por B. David, \& Thomas, pp. $27-$ 43. Walnut Creek:Left Coast Press Inc.

Fausto, C. 2001. Inimigos fiéis. São Paulo: EDUSP.

Ingold, T. 1993. The temporality of the landscape. World Archaeology 25:152-174.

Kern, D.C., G.D. D’Aquino, T.E. Rodrigues, F.J.L. Frazão, W. Sombroeck, T.P. Myers, e E.G. Neves. 2003. Distribution of Amazonian dark earths in the Brazilian Amazon, in Amazonian Dark Earths. Origin, properties, management. Editado por J. Lehmann, D.C. Kern, B. Glaser, \& W.I. Woods, pp. 51-76. Norwell: Kluwer Academic Publishers.

Knapp, A.B., \& W. Ashmore (Eds.). 1999. Archaeologies of landscapes: contemporary perspectives. Oxford: Blackwell Publishing.

Lane, P. 2008. Present to past, in Handbook of landscape archaeology. Editado por B. David, \& J. Thomas, pp. 402-424. Walnut Creek: Left Coast Press Inc.

Lukesh, A. 1976. Bearded Indians of the Tropical Forest. The Asurinis of the Ipiaçaba. Graz: Akad, Druck und Verlag Anst.

Müller, R. P. 1984/1985. Asuriní do Xingu. Revista de Antropologia 27/28: 91-114. 1987. De como cincoenta e duas pessoas reproduzem uma sociedade indigena. Os Asurini 
do Xingu. Tese de Doutorado. Programa de Antropologia Social, Departamento de Antropologia, Universidade de São Paulo, São Paulo/SP, Brasil. 1990. Os Asurini do Xingu (História e Arte). Campinas: Editora da UNICAMP.

Nimuendajú, C. 1948. Little-know Tribes of the Lower Tocantins River Region e Tribes of the Lower and Middle Xingu River, in Handbook of South American Indians. Editado por J. Stewart, pp. 213-242. Washington: Smithsonian Institution/Bureau of American Ethnology.

Ribeiro, B.G. 1982. A Oleira e a Tecelã. Revista de Antropologia, 26:25-61.

Ruibal, A.G. 2008. De la etnoarqueología a la arqueologia del presente, in Mundos tribales. Uma visión etnoarqueológica. Editado por J.Salazar; I.D. Sanz, J.M. Azkárraga, \& H. Bonet, pp. 16-27. Valência: Museu de Prehistória de Valência.

Shetler, J.B. 2007. Imagining Serengeti. A bistory of landscape memory in Tanzania from earliest times to the present. Athens: OhioUniversity Press.

Silva, F.A. 2002. Mito e arqueologia. A interpretação dos Asurini do Xingu sobre os vestígios arqueológicos encontrados no parque indígena Kuatinemu - Pará. Horizontes Antropológicos. Arqueologia e sociedades tradicionais 8(18): 175-187.

2003.Cultural behaviors of indigenous populations and the formation of the Archaeological record in Amazonian Dark Earth: The Asurini do Xingu case study, in Amazonian Dark Earths. Origin, properties, management. Editado por J. Lehmann, D.C. Kern, B. Glaser, \& W.I. Woods, pp. 373-385. Norwell: Kluwer Academic Publishers.

2011. O Patrimônio Arqueológico em Terras Indígenas: Algumas consideraçõessobre o tema no Brasil, in Patrimônio
Cultural no Brasil e na Argentina: estudos de caso. Editado por L.M. Ferreira, \& M.B. Rotman, pp. 193-219. São Paulo: Annablume.

2013. Território, lugares e memória dos Asurini do Xingu. Revista de Arqueologia 26(1): 28-41.

Silva, F. A., C. R. Appoloni, F. Quiñones, A. Santos, L. Silva, P. Barbieri, V. Nascimento. 2004. A Arqueometria e a análise de artefatos cerâmicos: um estudo de fragmentos cerâmicos etnográficos e arqueológicos por fluorescência de Raios X (EDXRF) e transmissão Gama. Revista de Arqueologia 17: 41-61.

Silva, F.A., E. Bespalez, e F.F. Stuchi. 2011. Arqueologia colaborativa na Amazônia: Terra Indígena Koatinemu, Rio Xingu, Pará. Amazônica - Revista de Antropologia $3(1): 32-59$.

Silva, J. P. 2012. A avaliação da diversidade de padrões de canais fluviais e da geodiversidade na Amarônia: Aplicação e Discussão na Bacia Hidrográfica do Rio Xingu. Tese de Doutorado, Departamento de Antropologia da Faculdade de Filosofia e Ciências Humanas, Universidade de São Paulo, Brasil.

Smith, N. 1980. Anthroposols and Human carrying capacity in Amazonia. Annals of the Association of American Geography 70 (4): 553-566.

Tilley, C. 1994. A phenomenology of landscape: places, paths, and monuments. Oxford: Berg.

Viveiros de Castro, E.B. 1986. Araweté: Deuses canibais. Rio de Janeiro: ZAHAR/ ANPOCS.

Whitridge, P. 2004. Landscapes, houses, bodies, things: place and the archaeology of Inuit Imaginaries. Journal of Archaeological Method and Theory 11(2):213-250.

Zedeño, M.N., \& B.J. Bowser. 2008. T h e archaeology of meaningful places. In: The archaeology of meaningful places. Editado por 
B.J. Bowser, \& M.N. Zedeño, pp. 1-14. Salt Lake City: The University of Utah Press.

Recebido em 01/08/2014.

Aprovado em 30/09/2014. 